УДК 621.774 .37

Король Р. Н.

\title{
ОСОБЕННОСТИ ОСНОВНЫХ ТЕХНОЛОГИЧЕСКИХ И КОНСТРУКТИВНЫХ ПАРАМЕТРОВ СТАЦИОНАРНОЙ КЛЕТИ СТАНА ХПТР ДЛЯ ОБЕСПЕЧЕНИЯ НЕПРИНУДИТЕЛЬНОГО ПРОЦЕССА ХОЛОДНОГО РЕДУЦИРОВАНИЯ ТРУБ
}

Способ холодного редуцирования труб на станах ХПТР применяется при изготовлении труб с особовысокой точностью по толщине стенки, наружному и внутреннему диаметрам [1], а также при изготовлении особотолстостенных труб методом «сочленения» [2].

К недостаткам применяемых рабочих клетей станов ХПТР можно отнести то, что протяженность хода подвижного сепаратора, в котором осуществляется деформация заготовки, меньше длины хода рабочей клети, а также подвижные части клети имеют большой вес, что, в свою очередь, ограничивает скорость прокатки, снижая тем самым производительность стана. Подвижная обойма рабочей клети обладает низкой жесткостью, что обуславливает значительную величину упругой деформации системы «рабочий инструмент - прокатная клеть». Это подтверждается расчетами, приведенными в работе [3].

Использование стационарной клети стана ХПТР с опорными катками для редуцирования особотонкостенных труб в начальный момент закатки переднего конца трубы может привести к его постоянному сплющиванию из-за большого веса опорных катков и рабочих роликов, нарушая, таким образом, стабильность процесса прокатки. К недостаткам клети следует отнести и трудоемкость изготовления опорных катков.

Целью работы является определение технологических и конструкционных особенностей стационарной клети стана ХПТР для обеспечения непринудительного процесса холодного редуцирования труб.

Для обеспечения вышеуказанного было предложено исключить из конструкции клети опорные катки и обеспечить свободное качение роликов по рабочему конусу, осуществить так называемый непринудительный процесс прокатки - при движении сепаратора ролики приводятся во вращение силами трения в очаге деформации, а их цапфы свободно перекатываются по рабочей калиброванной поверхности опорных планок.

Усовершенствованная рабочая клеть роликового стана холодной прокатки труб (рис. 1) содержит стационарный корпус (толстостенную обойму) 1 с расположенными в нем опорными планками 2 и подвижной сепаратор 3 с размещенными в нем рабочими роликами $4 \mathrm{c}$ ручьями постоянного профиля. Каждый ролик выполнен сборным в виде вала 5 с кольцевым выступом посередине его длины, на обеих сторонах которого расположены роликовые элементы качения 6 и 7, связанные между собой сепараторами 8 и 9, а на роликовые элементы качения посажено кольцо 10 с нарезанным по его окружности ручьем постоянного профиля; при этом к боковым сторонам кольца жестко прикреплены кольцевые крышки 11 и 12, а свободные концы вала 5 контактируют с рабочей калиброванной поверхностью опорных планок (рис. 2).

Такое решение позволяет существенно снизить вес подвижных частей клети, создавая возможности для увеличения числа двойных ходов клети в минуту. Кроме того, возможность удлинить протяженность обжимной зоны со снижением давления металла на ролик, а также увеличить толщину стенки неподвижной обоймы (в результате чего уменьшится ее упругая деформация, которая составляет до 70 \% от суммарной упругой деформации системы «рабочий инструмент - прокатная клеть»), позволяют повысить точность прокатываемых труб. 


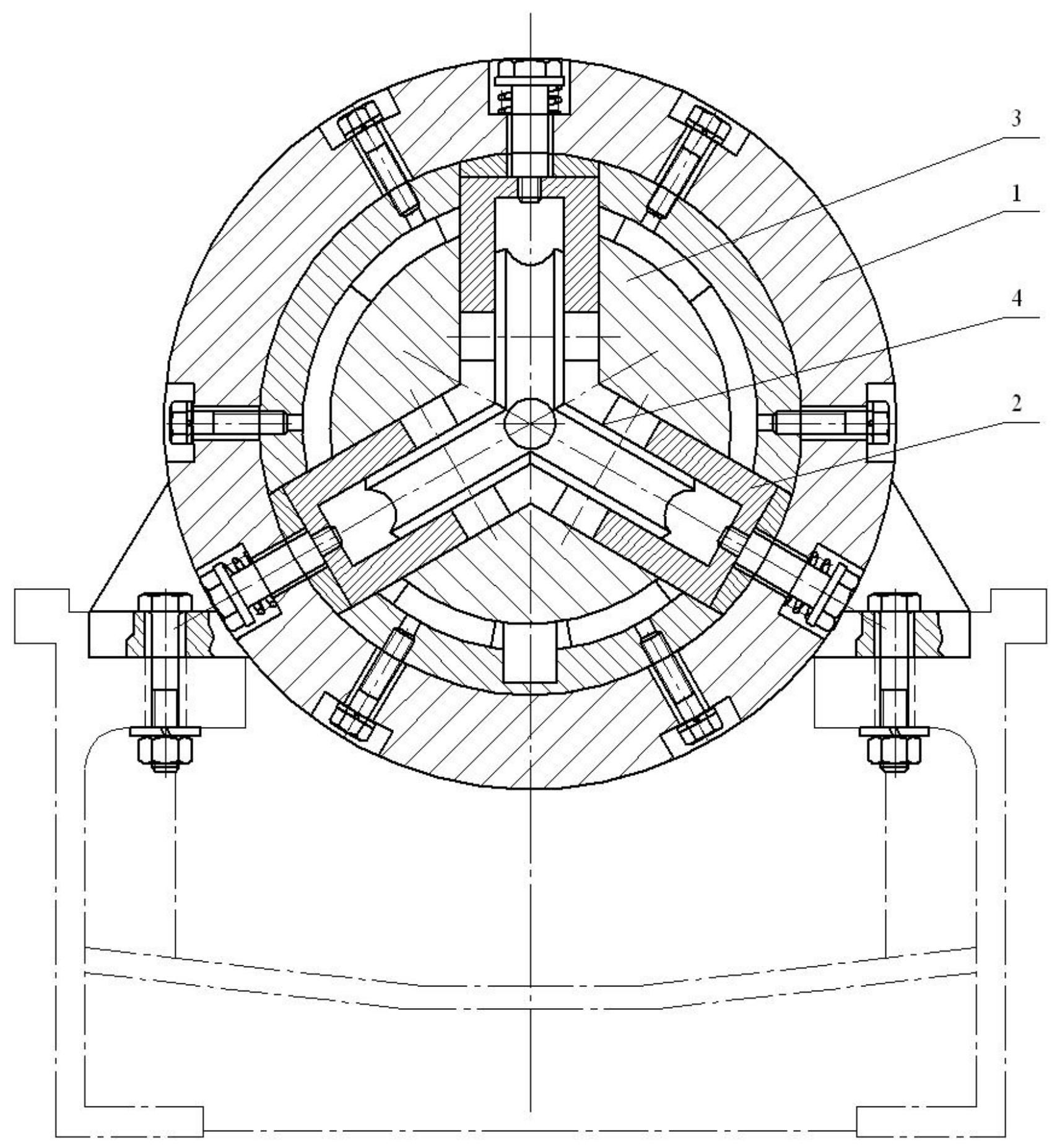

Рис. 1. Поперечное сечение усовершенствованной рабочей клети стана ХПТР с неподвижной обоймой:

1 - стационарный корпус клети; 2 - опорная планка; 3 - сепаратор; 4 - сборный рабочий ролик

Увеличение протяженности обжимной зоны приводит также к уменьшению деформации в мгновенном очаге, что позволяет прямопропорционально повысить величину подачи заготовки, а также увеличить дробность деформации. Последнее, как показали исследования, приведенные в работе [4], обеспечивает повышение точности и качества прокатываемых труб. 


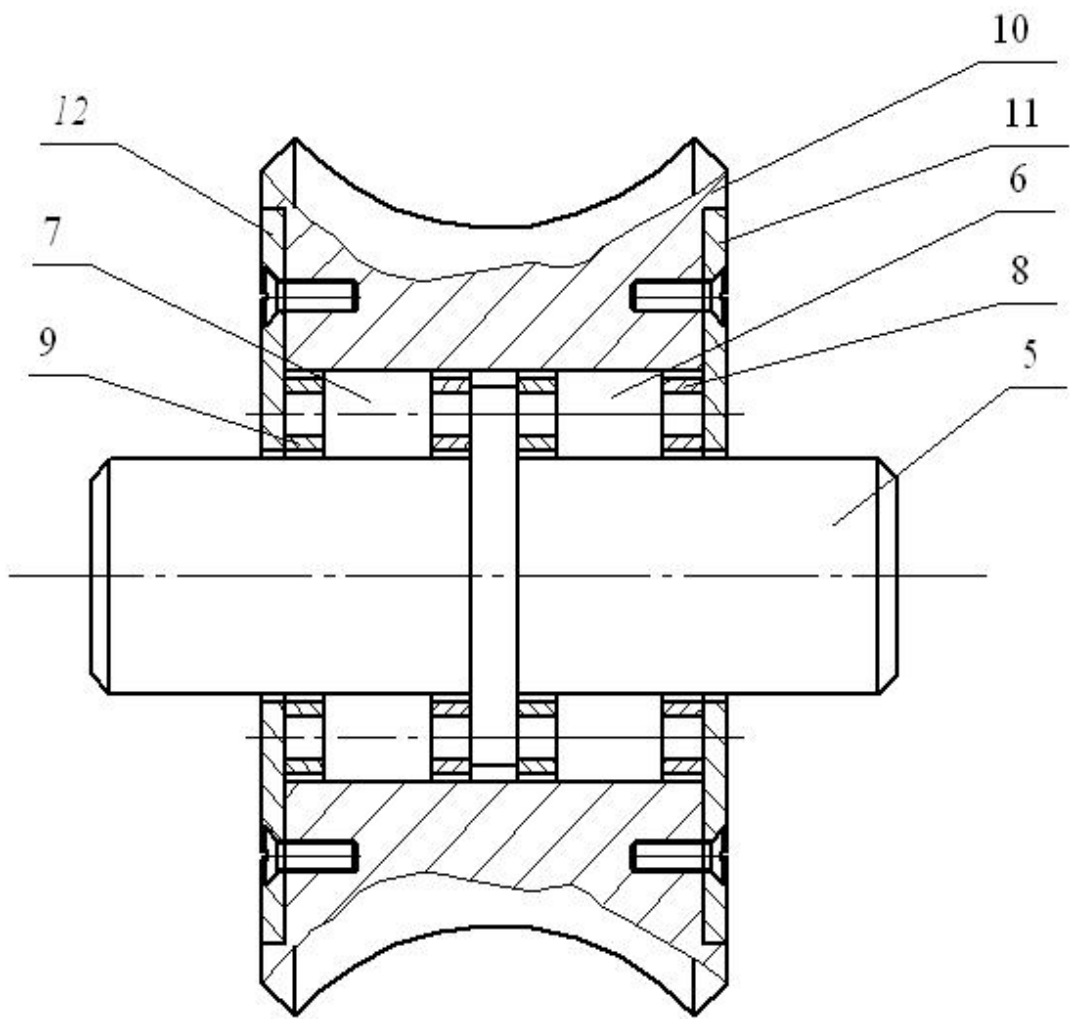

Рис. 2. Сборный ролик усовершенствованной рабочей клети стана ХПТР:

5 - вал с кольцевым выступом посередине; 6 и 7 - роликовые элементы качения; 8 и 9 - сепараторы; 10 - кольцо с нарезанным по его окружности ручьем постоянного профиля; 11 и 12 - кольцевые крышки

Установка усовершенствованной клети на действующие станы ХПТР не требует изменения всех остальных узлов стана, т.о. это связано с небольшими капитальными затратами.

Современное состояние технологии изготовления роликовых элементов качения обеспечивает нужные грузоподъемность и несущую нагрузку, вызванные давлением металла на рабочий ролик. Предварительно задаваясь габаритными размерами сплошных рабочих роликов, рассчитав максимальное давление металла на ролик в зоне обжатия по толщине стенки [4], можно определить размеры роликовых элементов качения, вала и кольца с нарезанным ручьем постоянного профиля. Дополнительную корректировку габаритных размеров рабочих роликов выполняют после проверки расчета вала на срез и допустимые контактные напряжения, а также кольца с нарезанным ручьем постоянного профиля на контактную прочность.

Выполненные расчеты сборных роликов показали, что имеется возможность уменьшить их размеры и вес в $1,3 \div 1,5$ раза по сравнению с существующими.

Усовершенствованная рабочая клеть роликового стана холодной прокатки труб работает следующим образом: расположенному в стационарном корпусе 1 сепаратору 3 с размещенными в нем рабочими роликами 4 через кривошипно-шатунный привод стана сообщают возвратно-поступательное перемещение. В момент нахождения сепаратора 3 в крайнем заднем положении, заготовка подается в очаг деформации, где осуществляется ее обжатие по диаметру и толщине стенки. Это приводит к возникновению давления метала на ручей постоянного профиля кольца 10, от которого давление передается через роликовые элементы качения 6 и 7, связанные между собой сепараторами 8 и 9, валу 5, прижимая его свободные концы к рабочей калиброванной поверхности опорных планок 2 и, как следствие, - вал 5 свободно перекатывается по рабочей калиброванной поверхности опорных планок 2 , 
а кольцо 10, благодаря действию на поверхность его ручья контактных сил трений, возникающих в очаге деформации, свободно перекатывается по рабочему конусу, осуществляя деформацию трубы во время «естественного» процесса прокатки. Жестко закрепленные кольцевые крышки 11 и 12 обеспечивают фиксацию кольца 10 на валу 5. Кольцо 10 с ручьем постоянного профиля и вал 5 свободно вращаются независимо один от другого с разной угловой скоростью.

Кинематическая схема взаимодействия вала, роликового элемента качения и кольца с нарезанным по его окружности ручьем постоянного профиля (сборный рабочий ролик) при прямом ходе сепаратора представлена на (рис. 3).

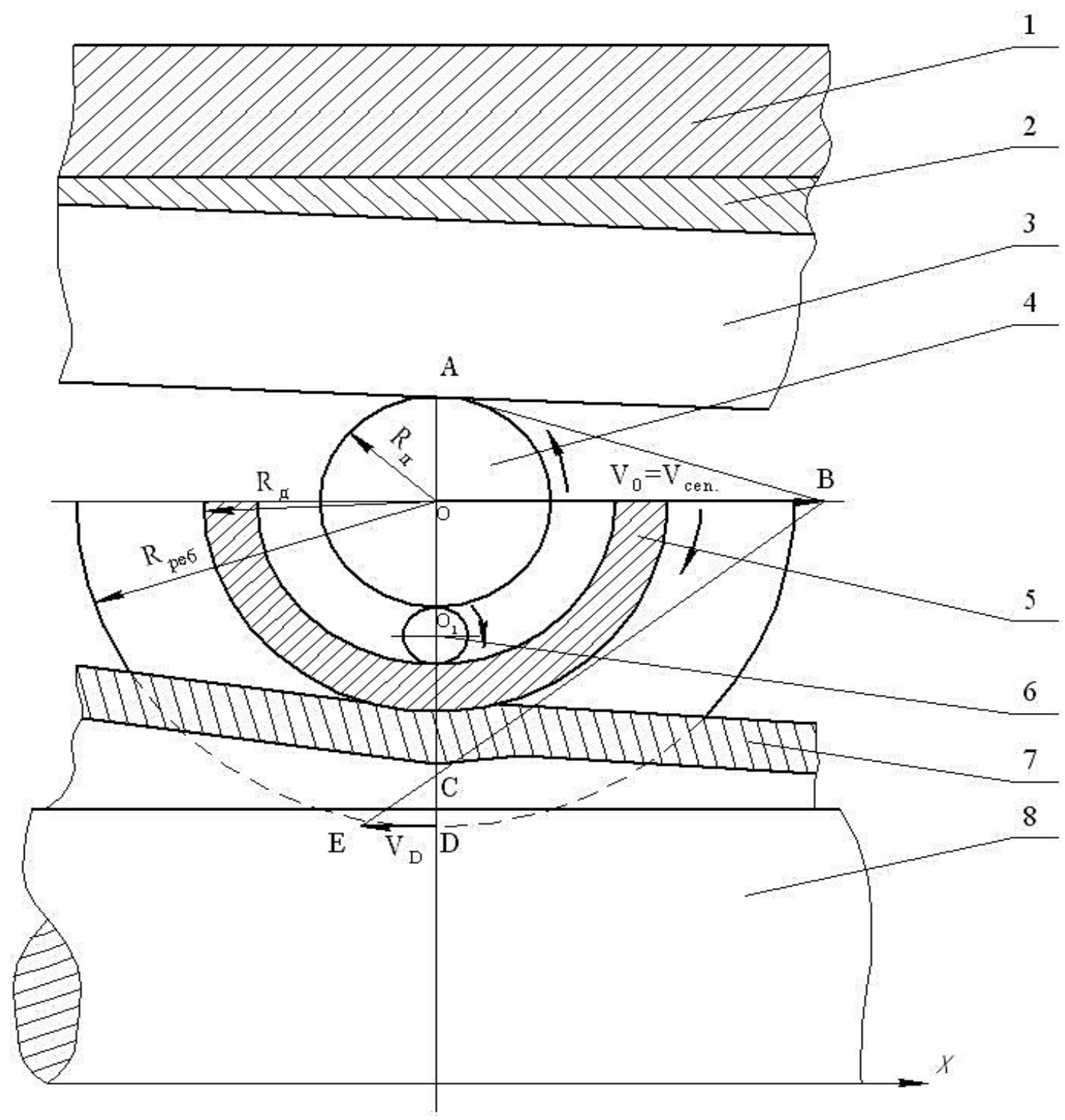

Рис. 3. Кинематическая схема взаимодействия вала, роликового элемента качения и кольца с нарезанным по его окружности ручьем постоянного профиля (сборный рабочий ролик) при прямом ходе сепаратора:

1 - стационарный корпус клети; 2 - регулировочный клин; 3 - опорная планка; 4 -вал; 5-кольцо с нарезанным по его окружности ручьем постоянного профиля; 6 - роликовый элемент качения; 7 - рабочий конус; 8 - цилиндрическая оправка;

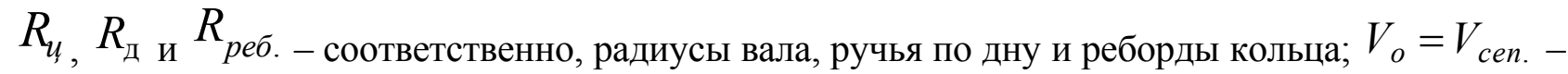
поступательная скорость сепаратора 
Естественный катающий радиус кольца является переменным и равен: $O C=R_{k} \neq$ const . Он определяется кинематическими условиями прокатки с учетом обжатия в мгновенном очаге деформации. Угловые скорости вала и кольца, соответственно, равны:

$$
W_{u}=\frac{V_{o}}{R_{u}}
$$

и

$$
W_{k}=\frac{V_{o}}{R_{k}}
$$

Тогда разность угловых скоростей кольца и вала будет равна:

$$
\Delta W=V_{o}\left(\frac{1}{R_{u}}-\frac{1}{R_{k}}\right) .
$$

Рассогласование этих скоростей не влияет на стабильность процесса прокатки, так как компенсаторами являются роликовые элементы качения. Определение естественного катающего радиуса кольца тесно связано с условиями соблюдения качения вала по калиброванной рабочей поверхности опорной планки и кольца сборного ролика по рабочему конусу. Вышеуказанные условия качения могут быть рассмотрены из схемы сил, действующих со стороны металла на кольцо сборного рабочего ролика.

\section{ВЫВОДЫ}

Применение стационарной клети стана ХПТР со сборным роликом с элементами качения позволяет добиться стабильности процесса прокатки при холодном редуцировании тонкостенных труб, а при изготовлении особотолстостенных труб методом «сочленения» обеспечить высокое качество поверхности и длительную стойкость рабочего инструмента за счет непринудительного ведения процесса прокатки.

\section{СПИСОК ИСПОЛЬЗОВАННОЙ ЛИТЕРАТУРЫ}

1. Король Р. Н. Рациональная технология уменьшения разностенности на тонкостенных и особотонкостенных трубах / Р. Н. Король // Металл и литье Украиныл. - 2007. - № 9-10. - С. 47-50.

2. Король Р. Н. Новая рацчинальная технология производства холоднодеформированных особотолстостенных труб мальх диаметров с высоким качеством внутренней поверхности / Р. Н. Король, Ю. М. Беликов, Н. Н. Мосьпан // Обработка металлов давлением : сб. науч. трудов. - Краматорск: ДГМА, 2012. - № 2 (31). C. 210-216.

3. Король Р. Н. Методика расчета суммарной упругой деформации рабочего ролика стана ХПТР / Р. Н. Король // Металл и литье Украиныл. - 2007. - № 4. - С. 21-27.

4. Король Р. Н. Обоснование, разработка и внедрение раџиональной технологии прокатки труб повышенной точности с использованием сварной заготовки на станах ХПТР : автореф. дис. на соиск. уч. степ. канд. техн. наук: спеи. 05.03.05 «Проиессы и машины обработки давлением» / Р. Н. Король. - Днепропетровск, 2009. $-20 \mathrm{c}$. 